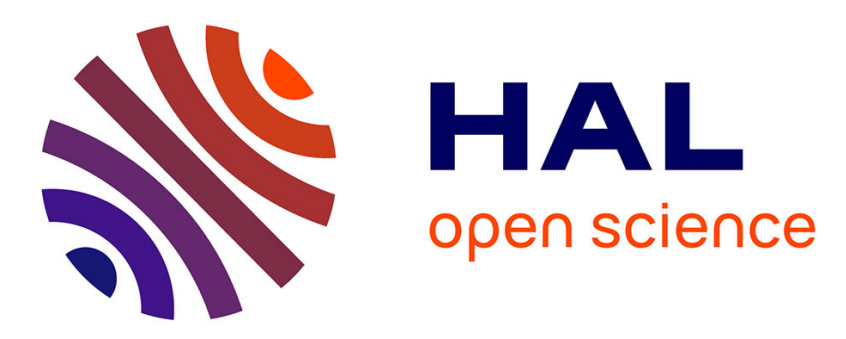

\title{
Removal Mechanisms of Contaminants in Ceramic Water Filters
}

\author{
Pierre-Marie Nigay, Ange Nzihou, Claire White, Winston Soboyejo
}

\section{To cite this version:}

Pierre-Marie Nigay, Ange Nzihou, Claire White, Winston Soboyejo. Removal Mechanisms of Contaminants in Ceramic Water Filters. Journal of Environmental Engineering, 2018, 144 (12), 10.1061/(ASCE)EE.1943-7870.0001471 . hal-01907681

\section{HAL Id: hal-01907681 https://imt-mines-albi.hal.science/hal-01907681}

Submitted on 22 Oct 2020

HAL is a multi-disciplinary open access archive for the deposit and dissemination of scientific research documents, whether they are published or not. The documents may come from teaching and research institutions in France or abroad, or from public or private research centers.
L'archive ouverte pluridisciplinaire HAL, est destinée au dépôt et à la diffusion de documents scientifiques de niveau recherche, publiés ou non, émanant des établissements d'enseignement et de recherche français ou étrangers, des laboratoires publics ou privés. 


\title{
Removal Mechanisms of Contaminants in Ceramic Water Filters
}

\author{
Pierre-Marie Nigay ${ }^{1}$; Ange Nzihou²; Claire E. White ${ }^{3}$; and Winston O. Soboyejo ${ }^{4}$
}

\begin{abstract}
In this paper, the removal mechanisms of organic (e.g., nitrate) and inorganic (e.g., lead) contaminants were investigated in ceramic water filters with organic (i.e., activated carbon) and inorganic (i.e., hydroxyapatite) additives. The ceramic water filters were characterized using atomic force microscopy, nitrogen sorption analysis, X-ray pair distribution function analysis, and scanning electron microscopy. It was found that adhesion controlled the efficiency of the ceramic water filters in the removal of contaminants. The conventional ceramic water filters had no adhesive interactions with the contaminants. A small amount of contaminants was removed by physical trapping in the pores. However, the addition of organic additives increased the adhesion between the organic contaminants and ceramic water filters (i.e., from 16 to $170 \mathrm{nN}$ ). This resulted in an increase of the efficiency from 0.9 to $6.7 \mathrm{mg} \cdot \mathrm{g}^{-1}$ in the removal of nitrate for a $20 \mathrm{wt} . \%$ addition of activated carbon. The removal of nitrate was completed once the surface was fully covered (surface adsorption mechanism). It was limited by the specific surface area of the materials. On the other hand, the inorganic additives increased the adhesive interactions of the ceramic water filters with the inorganic contaminants (i.e., from 33 to $153 \mathrm{nN}$ ). The efficiency in the removal of lead increased from 12.2 to $67.1 \mathrm{mg} \cdot \mathrm{g}^{-1}$ with a 2 wt.\% addition of hydroxyapatite. The removal was achieved by substitution of lead atoms $(\mathrm{Pb})$ for calcium atoms $(\mathrm{Ca})$ in the hydroxyapatite. Hence, the novelty of this work lies in the fact that doped ceramic water filters remove a wide range of contaminants from water via the combination of trapping, adsorption, and substitution mechanisms. Such filters are also suitable in terms of mechanical performances (i.e., 8.7 MPa) for application in household water treatment.
\end{abstract}

Keywords: Ceramic water filters; Activated carbon; Hydroxyapatite; Porosity; Permeability; Adhesion; Household water treatment.

\section{Introduction}

Currently, about 1 billion people across the world still do not have access to safe drinking water (WHO 2015). The water remains unsafe to drink in many developing countries due to the presence of contaminants at the point-of-use. The contaminants include bacteria (e.g., Escherichia coli, Legionella pneumophila) that may cause infectious diarrhea or lung infections (Brown et al. 2008; Ashbolt 2004); chemical substances (e.g., fluoride, lead) that may result in skeletal deformities or reduced intellectual ability (Meenakshi and Maheshwari 2006; Järup 2003); and viruses (hepatitis A) that may lead to liver disease (Franco et al. 2012). Worldwide, the presence of such contaminants in drinking water is responsible for the loss of more than 3 million lives per year (WHO 2001).

\footnotetext{
${ }^{1}$ Postdoctoral Researcher, Dept. of Mechanical Engineering, Worcester Polytechnic Institute, Worcester, MA 01609 (corresponding author). Email: pnigay@wpi.edu

${ }^{2}$ Professor, Centre RAPSODEE, Ecole des Mines d'Albi, Campus Jarlard, Route de Teillet, 81013 Albi Cedex 09, France. Email: ange .nzihou@mines-albi.fr

${ }^{3}$ Assistant Professor, Dept. of Civil and Environmental Engineering and Andlinger Center for Energy and the Environment, Princeton Univ., Princeton, NJ 08544. Email: whitece@princeton.edu

${ }^{4}$ Dean of Engineering, Professor, Dept. of Mechanical Engineering, Worcester Polytechnic Institute, Worcester, MA 01609. Email: wsoboyejo@ wpi.edu
}

The most effective approach that has been implemented is the point-of-use water treatment (Sobsey et al. 2008). In fact, contaminated water is purified at home by people or communities that do not have access to safe drinking water. The point-of-use approach includes different techniques such as boiling, chlorination, pasteurization, flocculation, or solar disinfection, as well as the use of biosand or ceramic water filters (Clasen et al. 2007; Hunter 2009; McGuigan et al. 1999). Among these techniques, ceramic water filters have high potential for a widespread use because they are easy to produce, easy to use, and highly efficient in the removal of bacteria (Fewtrell et al. 2005).

Typically, ceramic water filters are produced by mixing clay and water. Organic agents (e.g., sawdust, rice husk, and flour) can also be incorporated into the mixture (Oyanedel-Craver and Smith 2008). The resulting paste is molded in frustum-shape materials by applying compressive forces to the mixture between aluminum molds. After drying, the green bodies are sintered by firing at a temperature of approximately $900^{\circ} \mathrm{C}$ (Annan et al. 2014). The combustion of the organic agents results in the formation of interconnected pores that generate a flow path through the ceramic water filters.

When bacteria-contaminated water is introduced into the frustum-shaped filters, the water flows through the interconnected pores while the bacteria are trapped by nanoscale and micrometerscale pores that are present in the ceramic water filters (Yakub and Soboyejo 2012). Prior studies have shown that more than $99.9 \%$ of bacteria (e.g., Escherichia coli) can be removed from water when ceramic water filters are used in laboratory or service conditions (Yakub et al. 2013). This represents a significant step forward in improving the quality of drinking water. Nevertheless, the water may still be unsafe to drink due to a presence of chemical contaminants. 
The chemical contaminants can be removed by doping the ceramic water filters (Sullivan et al. 2017). In several studies, the removal of contaminants was achieved using hydroxyapatite-doped ceramic water filters (Yakub and Soboyejo 2013; Choudhary et al. 2014). The ceramic water filters removed up to $93 \%$ of the fluorides from the water. Although the removal of fluorides is now wellestablished, removal of other chemicals that can be found in water (e.g., arsenic, lead, mercury, nitrate, and sulfate) remains uncertain. The objective of this study is, therefore, to elucidate the removal mechanisms of ceramic water filters with organic (i.e., activated carbon) and inorganic (i.e., hydroxyapatite) additives to remove a wider range of contaminants from drinking water.

\section{Materials and Methods}

\section{Raw Materials}

The clay that was used in this study was extracted from a clay quarry in the Toulouse area of France. It was ground into particles with an average size of approximately $3 \mathrm{~mm}$ using a rolling mill (LA 1527, Vicentini, Vicenza, Italy). The elemental composition of the clay was measured using X-ray fluorescence (XRF) analysis (Epsilon 3-XL, PANalytical, Almelo, Netherlands). The results presented in Table 1 reveal a predominance of silicon and aluminum oxides, with smaller concentrations of calcium, iron, potassium, and magnesium oxides.

The additives that were used in this study consisted of activated carbon (AC) and hydroxyapatite (HA). The activated carbon was a commercial product (Darco G-60) obtained from Sigma-Aldrich Company (St. Louis, Missouri). The elemental composition of the activated carbon, measured using a Flash 2000 Organic Elemental Analysis (OEA) apparatus (Thermo Fisher Scientific, Waltham, Massachusetts) is given in Table 2. The results show that carbon is the predominant element in the sample. The hydroxyapatite was a commercial product (TCP 908) obtained from Prayon (Engis, Belgium). It is seen to consist of calcium and phosphorus oxides with residual oxides of sodium (Table 1), as measured using XRF analysis.

The particle-size distribution of the additives was measured via laser granulometry analysis (Mastersizer 3000, Malvern Instruments, Malvern, UK). The results of the analysis are presented in Fig. 1 and show an average particle size of $60 \mu \mathrm{m}$ for the activated carbon and a smaller average particle size of $5 \mu \mathrm{m}$ for the hydroxyapatite.

Table 1. Elemental composition of the clay and hydroxyapatite (HA) obtained using XRF analysis

\begin{tabular}{lrrrcccr}
\hline & \multicolumn{7}{c}{ Concentration (wt.\%) } \\
\cline { 2 - 8 } Sample & $\mathrm{SiO}_{2}$ & $\mathrm{Al}_{2} \mathrm{O}_{3}$ & $\mathrm{CaO}$ & $\mathrm{Fe}_{2} \mathrm{O}_{3}$ & $\mathrm{MgO}$ & $\mathrm{Na}_{2} \mathrm{O}$ & $\mathrm{P}_{2} \mathrm{O}_{5}$ \\
\hline Clay & 57.1 & 14.5 & 8.9 & 6.2 & 2.2 & 0.6 & 0.0 \\
$\mathrm{HA}$ & 0.0 & 0.1 & 58.5 & 0.0 & 1.0 & 5.7 & 27.1 \\
\hline
\end{tabular}

Table 2. Elemental composition of the activated carbon (AC) obtained using OEA analysis

\begin{tabular}{lccccc}
\hline & \multicolumn{5}{c}{ Concentration (wt.\%) } \\
\cline { 2 - 6 } Sample & C & H & O & N & S \\
\hline AC & 86.1 & 0.5 & 2.9 & 0.4 & 0.0 \\
\hline
\end{tabular}

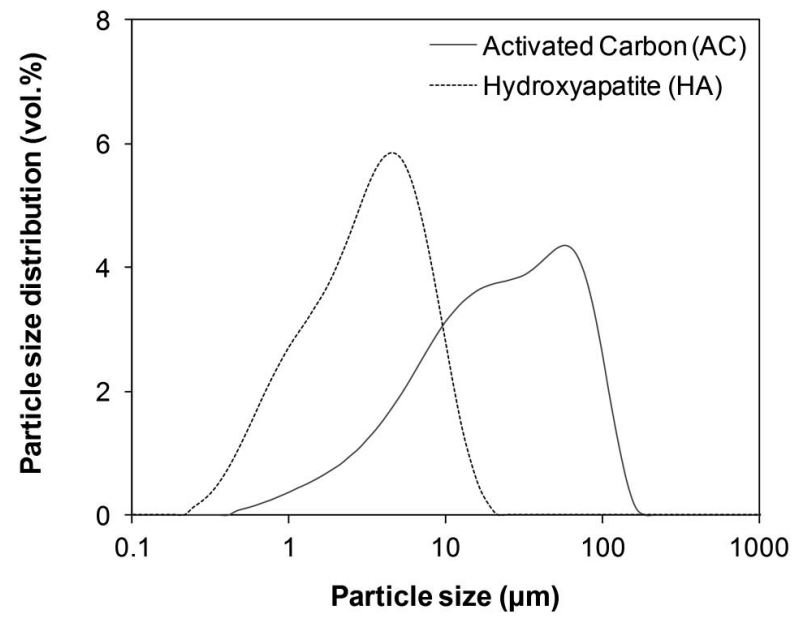

Fig. 1. Particle-size distribution of $\mathrm{AC}$ and $\mathrm{HA}$ obtained using laser granulometry analysis.

\section{Processing of the Ceramic Water Filters}

The ceramic water filters that were investigated in this study were produced from different mixtures of clay with organic/inorganic additives and water. The mixtures were prepared in a kneading bowl by mixing the clay with 10 or $20 \mathrm{wt} . \%$ of activated carbon (organic additive) or hydroxyapatite (inorganic additive). Water was added to the mixtures (under kneading) until a plastic paste was formed (i.e., 28 wt.\% of water).

Subsequently, the mixtures were extruded with a bench extruder (Reber, Correggioverde di Dosolo, Italy), composed of a pipe and a crank-activated piston. They were pushed into the pipe and released across a die as blocks with dimensions of $60 \times 30 \times 10 \mathrm{~mm}^{3}$. The blocks were then incrementally dried at $25^{\circ} \mathrm{C}, 65^{\circ} \mathrm{C}$, and $105^{\circ} \mathrm{C}$ for $24 \mathrm{~h}$ at each temperature in an electrical oven (Memmert, Schwabach, Germany). In this study, extrusion was preferred over hydraulic pressing. It produced a great number of uniform blocks instead of frustum-shaped materials. Typically, these blocks were equivalent to the circumference of the conventional materials.

Finally, the different samples that were tested in this study were prepared from the dried blocks using P80, P120, P180, and P280 SiC abrasive papers (CarbiMet, Buehler, Uzwil, Switzerland). Some of the samples were also fired at a temperature of $950^{\circ} \mathrm{C}$ in a nitrogen atmosphere (flow of $5 \mathrm{~L} / \mathrm{min}$ ). The samples were fired in a sealed box that was placed in a muffle furnace (K1253, Heraeus, Hanau, Germany).

\section{Characterization of the Ceramic Water Filters}

The thermal behavior of the ceramic water filters was determined via thermogravimetric analysis (TGA). The determination of the mass loss as a function of the temperature was obtained using a Q600 apparatus (TA Instruments, New Castle, Delaware). The data were collected in an air atmosphere using unfired samples with a mass of around $200 \mathrm{mg}$. The thermal analyses were carried out at temperatures between $30^{\circ} \mathrm{C}$ and $1,100^{\circ} \mathrm{C}$ with a $5^{\circ} \mathrm{C} / \mathrm{min}$ heating rate. Finally, the dependence of the percentage of additives on the firing temperature was determined by subtracting the mass loss of the ceramic water filters from the mass loss of the ceramic water filter without any additives.

The distribution of the additives in the ceramic water filters was observed via scanning electron microscopy (SEM), using a tabletop TM3030Plus microscope (Hitachi, Tokyo, Japan). The samples 
were embedded in a solidifying epoxy resin and polished before imaging. The imaging was performed under backscattered electron (BSE) imaging conditions using an acceleration voltage of $15 \mathrm{kV}$ and working distance of $10 \mathrm{~mm}$.

The porosity of the ceramic water filters was measured using a water absorption technique and fired samples with dimensions of $30 \times 30 \times 5 \mathrm{~mm}^{3}$. The samples were introduced in a desiccator and subjected to a vacuum pressure of $30 \mathrm{kPa}(4 \mathrm{~h})$. This was followed by partial immersion $(2 \mathrm{~h})$ and full immersion $(24 \mathrm{~h})$ of the samples in water under the same vacuum pressure. The atmospheric pressure was then restored in the desiccator, where the samples remained fully immersed for an additional $24 \mathrm{~h}$. Following this operation, the mass of the samples was measured under water (i.e., hydrostatic weighing), under air after wet wiping, and under air after drying at a temperature of $105^{\circ} \mathrm{C}$ to estimate the volume fraction of connected pores. The estimates were obtained from Eq. (1)

$$
\varepsilon_{\text {connected }}=\frac{m_{w}-m_{d}}{m_{w}-m_{h}}
$$

where $m_{h}=$ hydrostatic mass; $m_{w}=$ wet mass; and $m_{d}=$ dry mass.

The previous data were also used to estimate the total volume fraction of pores, $\varepsilon_{\text {total }}$. The estimates were obtained from Eq. (2). The dry volume was determined using a Vernier caliper, and the true density was measured via helium pycnometry analysis (Accupyc 1330, Micromeritics, Norcross, Georgia). The measurements of the true density were carried out after firing at the maximum temperature of $1,100^{\circ} \mathrm{C}$ and grinding to eliminate the porosity of the samples

$$
\varepsilon_{\text {total }}=1-\frac{m_{d} / V_{d}}{\rho_{\text {true }}}
$$

where $V_{d}=$ dry volume; and $\rho_{\text {true }}=$ true density.

The type of porosity within the ceramic water filters was determined from gas adsorption theory. The analyses were performed in a Tristar II 3020 system (Micromeritics, Norcross, Georgia) using nitrogen as the adsorptive and cylindrical samples with a mass of $1 \mathrm{~g}$. The samples were cleaned via heating under vacuum at $180^{\circ} \mathrm{C}$ for $12 \mathrm{~h}$. Following the gas adsorption analyses, the poresize distributions were calculated using the Barrett-Joyner-Halenda method (BJH) (Barrett et al. 1951). The Brunauer-Emmett-Teller (BET) method was used to estimate the specific surface areas of the samples (Brunauer et al. 1938).

The permeability of the ceramic water filters, $k$, was calculated from Eq. (3) (Katz and Thompson 1987)

$$
k=\frac{1}{89} \frac{\left(l_{\max }\right)^{3}}{l_{c}} f\left(l_{\max }\right) \varepsilon_{\text {connected }}
$$

where $l_{c}=$ pore diameter for which the flow is minimum (critical); $l_{\max }=$ pore diameter for which the flow is maximum; $f\left(l_{\max }\right)=$ volume fraction of pores with a diameter equal to or larger than $l_{\max }$; and $\varepsilon_{\text {connected }}=$ volume fraction of connected pores.

The volume fraction of connected pores was obtained from the water absorption technique [Eq. (1)]. On the other hand, the pore diameter for which the flow is minimum, the pore diameter for which the flow is maximum, and the volume fraction of pores with a diameter equal to the pore diameter for which the flow is maximum or larger were determined using mercury intrusion porosimetry (Autopore IV, Micromeritics, Norcross, Georgia). They were equal to $0.021 \mu \mathrm{m}, 0.66 \mu \mathrm{m}$, and 0.54 for all the ceramic water filters. Further details on the determination of $l_{c}, l_{\max }$, and $f\left(l_{\max }\right)$ can be found in the literature (Nishiyama and Yokoyama 2014).

\section{Determination of the Removal Efficiency/Mechanisms}

The removal of chemicals from the contaminated water was investigated using aqueous solutions of organic (nitrate) and inorganic (lead) contaminants. These were prepared by dissolution of sodium nitrate and lead acetate (Sigma-Aldrich, St. Louis, Missouri) in deionized water. The concentration of nitrate (i.e., $\mathrm{NO}_{3}^{-}$) and lead (i.e., $\mathrm{Pb}$ ) was equal to $1,000 \mathrm{ppm}$ (i.e., $1 \mathrm{~g} \cdot \mathrm{L}^{-1}$ ). Typically, the aqueous solutions were introduced into beakers that contained fired samples of $1 \mathrm{~g}$. They were subjected to a vacuum pressure of $30 \mathrm{kPa}$ for $1 \mathrm{~h}$ to promote penetration into the pores and simulate the percolation mechanism. The procedure was established from a previous study (Yakub and Soboyejo 2013). In fact, the contact time was chosen as long enough to reach the uptake equilibrium (i.e., $1 \mathrm{~h}$ ) and short enough compared with the filtration time.

Following this operation, the concentration of nitrate and lead in the aqueous solutions of contaminants was measured using ion chromatography (ICS-2100, Dionex, Sunnyvale, California) and inductively coupled plasma mass spectrometry (NexION 350X, PerkinElmer, Waltham, Massachusetts), respectively. The final concentration was also compared with the initial concentration. Hence, the removal efficiency was determined from the weight difference of contaminants per unit mass of sample.

The removal mechanisms were elucidated by measuring the adhesion forces between the ceramic water filters and contaminants. The measurements were performed via atomic force microscopy (AFM) using a Dimension 3100 system (Digital Instruments, Bresso, Italy) with AFM-contaminant-coated probes (MPP3110010, Bruker, Camarillo, California) and fired samples with dimensions of $10 \times 10 \times 5 \mathrm{~mm}^{3}$. The AFM-contaminant-coated probes were prepared by placing a drop of aqueous solution of contaminants on the cantilever. The self-assembly of the contaminants onto the AFM probes was completed via $2 \mathrm{~h}$ of drying in a desiccator (Prater et al. 1995). Following this operation, the adhesion forces were measured in the AFM system under contact mode. The values were obtained from the deflection-displacement behaviors by multiplying the pull-off deflections by the spring constant of the AFM probes (i.e., $0.9 \mathrm{~N} \cdot \mathrm{m}^{-1}$ ). It is important to mention that the accuracy was controlled by testing the pull-off deflections with AFM-non-coated probes.

The removal mechanisms were also elucidated via SEM (Quanta FEG 200, FEI, Hillsboro, Oregon). The SEM observations were conducted on cross sections of the ceramic water filters and surfaces of the additives after the removal of contaminants. The density-dependent color (DDC-SEM) micrographs were obtained via combination of secondary electron (SE) and BSE imaging at an acceleration voltage of $10 \mathrm{kV}$ and a working distance of approximately $10 \mathrm{~mm}$.

The chemical form of the contaminants was determined using X-ray diffraction (XRD). The XRD analyses were carried out after the removal of contaminants and the grinding of the samples with a mortar and pestle. Each sample was loaded into a $1 \mathrm{~mm}$-diameter polyimide capillary, which was sealed at both ends with modeling clay. The sample was then aligned on the capillary stage of the diffractometer (D8 Advance, Bruker, Madison, Wisconsin) and tested while spinning. The data were collected over a $2 \theta$ range of $2^{\circ}-130^{\circ}$, with a step size of $0.05^{\circ}$ and a count time per step of $30 \mathrm{~s}$, using a silver $(\mathrm{Ag})$ radiation source ( $\lambda=0.56 \AA$ ). The crystalline phases were identified using the Bruker EVA Suite 3.1 software package. This was done by matching the International Centre for Diffraction Data (ICDD) database files to Bragg peaks 


$$
G(r)=\frac{2}{\pi} \int_{Q_{\min }}^{Q_{\max }} Q[S(Q)-1] \sin (Q r) d Q
$$

The XRD patterns were also used to produce the X-ray pair distribution function (PDF) curves of the samples. The background was initially removed using the scattering from an empty capillary. Subsequently, a sine Fourier transform [Eq. (4)] was applied to the total scattering functions $S(Q)$ using the PDFgetX2 1.0 software (Qiu et al. 2004). The PDFs of the samples were all obtained using a maximum momentum transfer $Q_{\max }$ of $15 \AA^{-1}$.

\section{Determination of the Mechanical Properties}

The mechanical properties of the ceramic water filters were measured in an Instron 8548 microtester (Instron, Norwood, Massachusetts). The measurements were performed using a threepoint-bending test fixture (load span of $50 \mathrm{~mm}$ ) and a 500-N load cell. Specimens with dimensions of $60 \times 10 \times 5 \mathrm{~mm}^{3}$ were subjected to a constant displacement rate of $1 \mathrm{~mm} / \mathrm{min}$ until the onset of the fracture. The flexural strength, $\sigma$, was estimated from Eq. (5) (ASTM 2010)

$$
\sigma=\frac{3 F_{\mathrm{Max}} L}{2 B H^{2}}
$$

where $F_{\text {Max }}=$ maximum force; $L=$ loading span; $B=$ breadth; and $H=$ height of the specimens.

The statistical analysis of the flexural strength data was carried out using the results of 25 tests. The probability of failure, $P_{f}[X]$, was calculated from Eq. (6)

$$
P_{f}[X]=\sum_{i=0}^{X} f_{f}[i]
$$

where $f_{f}[i]=$ frequency of failure for each stress level.

The distribution of the strength was predicted using the Weibull distribution analysis. The probability density function, $F(\sigma)$, was obtained from Eq. (7)

$$
F(\sigma)=\frac{m}{\sigma_{0}}\left(\frac{\sigma}{\sigma_{0}}\right)^{m-1} e^{-\left(\sigma / \sigma_{0}\right)^{m}}
$$

where $\sigma=$ stress applied; $\sigma_{0}=$ scale parameter; and $m=$ shape parameter (i.e., Weibull modulus) (Weibull 1951).

The preceding parameters were determined by plotting $\ln \left\{\ln \left[1 /\left(1-P_{f}[X]\right)\right]\right\}$ versus $\ln [X]$ with the measured values of the strength (Davies 2017). The shape parameter $(m)$ was equivalent to the slope of the plot (i.e., 12.00). Furthermore, the scale parameter $\left(\sigma_{0}\right)$ was equivalent to the exponential of the intercept over the shape parameter (i.e., 8.89).

\section{Results and Discussion}

\section{Structure of the Ceramic Water Filters}

The thermal behavior of the ceramic water filters after subtraction of the clay-based transformations (i.e., dehydration, dehydroxylation, decarbonation, and sintering) is presented in Fig. 2. The results show that the ceramic water filter with $20 \mathrm{wt} . \%$ addition of hydroxyapatite is not subjected to thermal degradation at temperatures between $30^{\circ} \mathrm{C}$ and $1,100^{\circ} \mathrm{C}$. Typically, the hydroxyapatite remains unchanged within the clay matrix. The pyrolysis of activated carbon results in a transformation of carbon, oxygen, and hydrogen elements into $\mathrm{CO}, \mathrm{CO}_{2}, \mathrm{CH}_{4}$, and $\mathrm{H}_{2}$, which are released

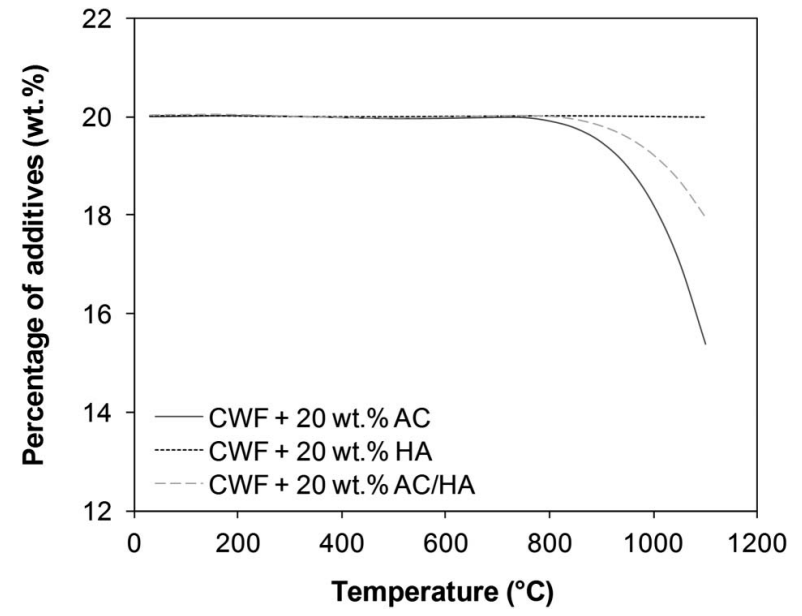

Fig. 2. Dependence of the percentage of additives on the firing temperature of the ceramic water filter $(\mathrm{CWF})$ with $20 \mathrm{wt} \%$ addition of AC, HA, or AC/HA. Data were obtained using TGA analysis.

in the form of gas during the firing process (Di Blasi 2008). Nevertheless, the transformation of the activated carbon does not occur extensively at temperatures below $900^{\circ} \mathrm{C}$. This means that the activated carbon is kept unchanged in the ceramic water filter after firing at $950^{\circ} \mathrm{C}$ (i.e., temperature used for the processing). Hence, the $20 \mathrm{wt} . \%$ addition of activated carbon and hydroxyapatite does not significantly modify the thermal behavior of the ceramic water filters either.

The SEM micrographs obtained after firing of the ceramic water filters at a temperature of $950^{\circ} \mathrm{C}$ are presented in Fig. 3. The images show that the ceramic water filter without additive has a heterogeneous structure of fired clay with pores and quartz particles. The pores correspond to the air, which is retained in the ceramic water filter during the extrusion process. They are relatively small defects in the structure, with average dimensions of $10 \mu \mathrm{m}$, compared with the decohesions around the quartz particles, with dimensions varying from 50 to $200 \mu \mathrm{m}$. These decohesions result from the deformation mismatch between the fired-clay matrix and the quartz particles during the cooling of the materials (Tarvornpanich et al. 2008). The 20 wt. $\%$ addition of activated carbon in the ceramic water filter results in a modification of the structure. The ceramic water filter conserves the $10 \mu \mathrm{m}$ pores associated with the extrusion process and the 50-200 $\mu \mathrm{m}$ decohesions around the quartz particles. The particles of activated carbon are also well dispersed in the clay matrix. However, they conserve their average dimensions of $60 \mu \mathrm{m}$, which make them important defects in the structure. The $20 \mathrm{wt} . \%$ addition of hydroxyapatite does not result in any significant modification of the structure. This can be attributed to the small particle size of hydroxyapatite, with an average diameter of $5 \mu \mathrm{m}$. Hence, the structure of the ceramic water filter with 20 wt.\% addition of activated carbon and hydroxyapatite is only modified by the particles of activated carbon at the microscopic scale.

The pore-size distributions obtained after firing of the ceramic water filters at $950^{\circ} \mathrm{C}$ are presented in Fig. 4. The results show that the ceramic water filter without additives does not have a significant fraction of pores at the nanoscale. This means that the porosity is limited to the microscopic pores of $10 \mu \mathrm{m}$ that result from the extrusion process. On the other hand, the ceramic water filter with $20 \mathrm{wt} . \%$ addition of activated carbon has an important fraction of pores at the nanoscale. These pores with an average diameter of 


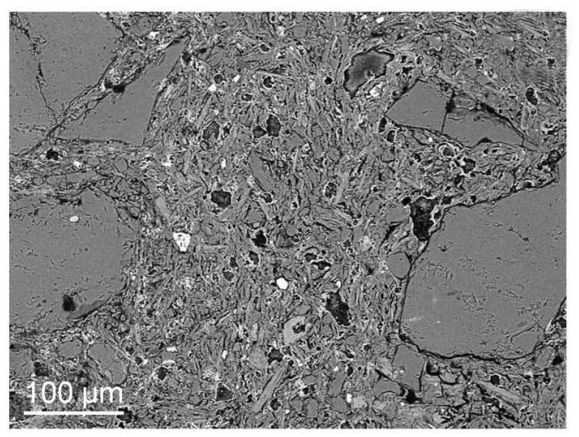

(a)

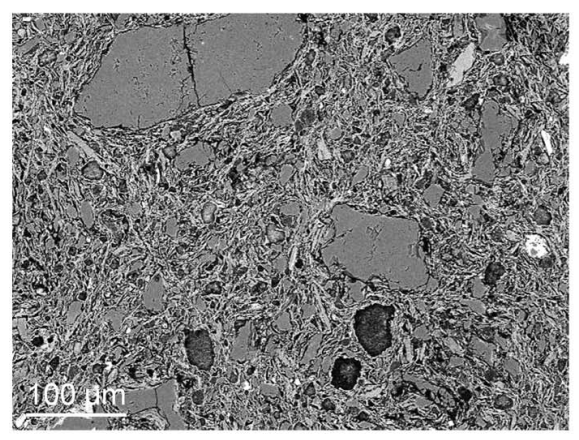

(c)

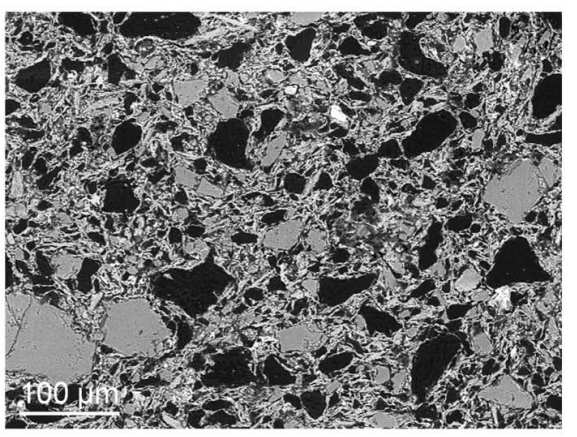

(b)

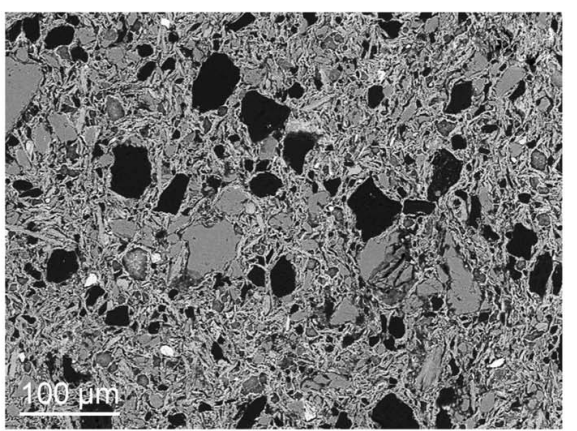

(d)

Fig. 3. SEM micrographs of (a) CWF without additives; (b) CWF with 20 wt.\% addition of activated carbon; (c) hydroxyapatite; and (d) activated carbon and hydroxyapatite after firing of the ceramic water filters at $950^{\circ} \mathrm{C}$ in an air atmosphere.

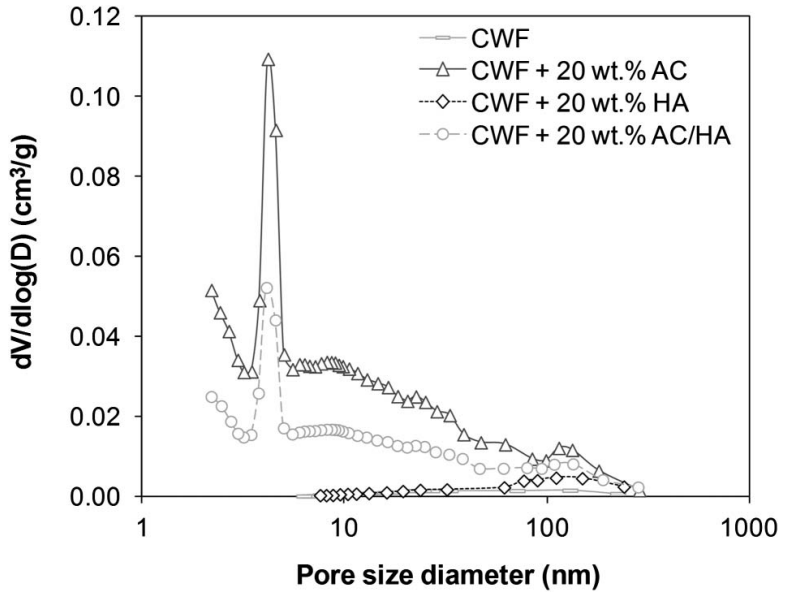

Fig. 4. Pore-size distribution of CWF without additives and CWF with 20 wt. $\%$ addition of $\mathrm{AC}, \mathrm{HA}$, or $\mathrm{AC} / \mathrm{HA}$ after firing of the ceramic water filters at $950^{\circ} \mathrm{C}$ in an air atmosphere. Data were obtained using nitrogen adsorption analysis and the BJH method.

$5 \mathrm{~nm}$ correspond to the pores of the activated carbon. They come in addition to the microscopic pores from the clay matrix. Similarly, the $20 \mathrm{wt} . \%$ addition of hydroxyapatite results in the emergence of a new fraction of pores at the nanoscale. These nanopores have a larger average pore-size diameter (i.e., approximately $100 \mathrm{~nm}$ ) than those of the activated carbon (i.e., $5 \mathrm{~nm}$ ). This means that the ceramic water filter with 20 wt.\% addition of activated carbon and hydroxyapatite has a wide range of pore sizes with diameters between 5 and $100 \mathrm{~nm}$ at the nanoscale and $10 \mu \mathrm{m}$ at the microscopic scale.
Table 3. Total porosity, open porosity, permeability, and specific surface area of CWF without additives and with $20 \mathrm{wt}$.\% addition of AC, HA, or $\mathrm{AC} / \mathrm{HA}$ after firing the $\mathrm{CWF}$ at $950^{\circ} \mathrm{C}$ in an air atmosphere

\begin{tabular}{lcccc}
\hline Sample & $\begin{array}{c}\text { Total } \\
\text { porosity } \\
(\text { vol.\%) }\end{array}$ & $\begin{array}{c}\text { Open } \\
\text { porosity } \\
(\text { vol.\%) }\end{array}$ & $\begin{array}{c}\text { Permeability } \\
(\mathrm{mD})\end{array}$ & $\begin{array}{c}\text { Specific } \\
\text { surface area } \\
\left(\mathrm{m}^{2} \cdot \mathrm{g}^{-1}\right)\end{array}$ \\
\hline CWF & 34 & 27 & 23 & 0.9 \\
CWF + 20 & 57 & 52 & 43 & 194.7 \\
$\begin{array}{l}\text { wt.\% AC } \\
\text { CWF + 20 }\end{array}$ & 40 & 35 & 30 & 12.3 \\
wt.\% HA & 49 & 44 & 37 & 94.8 \\
CWF + 20 & 49 . & & & \\
wt.\% AC/HA & & &
\end{tabular}

Note: Data were obtained using water absorption analysis (porosity), mercury intrusion porosimetry (permeability), and nitrogen adsorption analysis with the BET method (specific surface area).

The physical properties of the ceramic water filters obtained after firing at $950^{\circ} \mathrm{C}$ are summarized in Table 3 . The results show that the ceramic water filter without additives has a porosity of $34 \mathrm{vol} . \%$, with a volume fraction of connected pores equal to $27 \%$. Typically, the filter has a permeability of $23 \mathrm{mD}$ and specific surface area of $0.9 \mathrm{~m}^{2} \cdot \mathrm{g}^{-1}$. The $20 \mathrm{wt} . \%$ addition of activated carbon increases the volume fraction of pores to $57 \%$, with 52 vol. $\%$ of connected pores. The greater fraction of connected pores results in a significant increase of the permeability to $43 \mathrm{mD}$. Furthermore, the small pores of the activated carbon (i.e., $5 \mathrm{~nm}$ ) provide a high specific surface area of $194.7 \mathrm{~m}^{2} \cdot \mathrm{g}^{-1}$ to the ceramic water filters. The $20 \mathrm{wt} . \%$ addition of hydroxyapatite induces a smaller increase of the volume fraction of connected pores (i.e., 35\%) with larger pores of $100 \mathrm{~nm}$. This results in a lower permeability of $30 \mathrm{mD}$ and a lower specific surface area of $12.3 \mathrm{~m}^{2} \cdot \mathrm{g}^{-1}$ compared with 


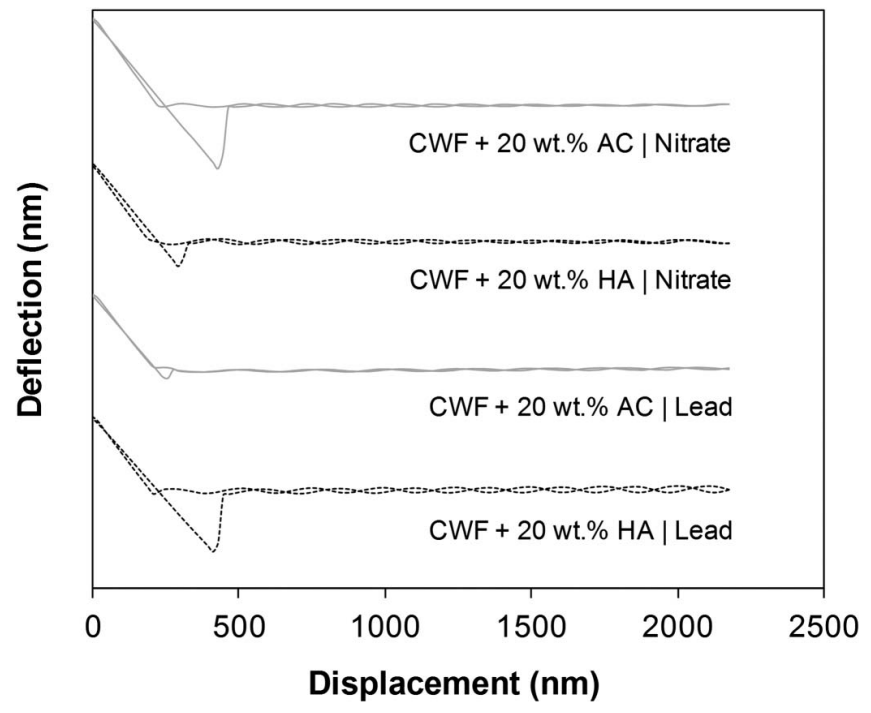

Fig. 5. Stacked plot of the deflection-displacement behavior of the AFM-contaminant-coated probes (nitrate and lead) on the CWF with 20 wt.\% addition of AC or HA.

the addition of activated carbon. Nevertheless, the ceramic water filter with $20 \mathrm{wt}$ \% addition of activated carbon and hydroxyapatite conserves, as a combination of the respective materials, a high permeability (i.e., $37 \mathrm{mD}$ ) and a high specific surface area (i.e., $94.8 \mathrm{~m}^{2} \cdot \mathrm{g}^{-1}$ ).

\section{Removal Efficiency/Mechanisms of the Ceramic Water Filters}

The deflection-displacement behavior of the AFM-nitrate-coated and AFM-lead-coated probes on the ceramic water filters obtained after firing at a temperature of $950^{\circ} \mathrm{C}$ are presented in Fig. 5 . The results show that as the AFM-coated probes approach the ceramic water filters (i.e., decrease in the distance) there is a jump to contact (i.e., increase in the deflection) that is similar for both contaminants. However, it can be observed that the AFM-coated probes do not detach in the same way (i.e., decrease in the deflection) during retraction (i.e., increase in the distance). The differences in the approach and retraction of the AFM-coated probes (i.e., pull-off) are due to the different adhesive interactions that occur between the contaminants on the probe and the ceramic water filters. The results indicate that nitrate (i.e., organic contaminant) and the ceramic water filter with a $20 \mathrm{wt} . \%$ addition of activated carbon (i.e., organic additives) have strong adhesive interactions. Strong adhesive interactions can also be observed between lead (i.e., inorganic contaminant) and the ceramic water filter with 20 wt. $\%$ addition of hydroxyapatite (i.e., inorganic contaminant).

The adhesion forces that occur between the contaminants and ceramic water filters obtained after firing at $950^{\circ} \mathrm{C}$ are presented in Fig. 6. It can be observed that nitrate and lead do not have strong adhesion forces with the ceramic water filter without additives. The adhesion forces are limited to 16 and $33 \mathrm{nN}$, respectively. For the ceramic water filters with additives, the results confirm the previous observations in Fig. 5. Nitrate has a strong affinity for the ceramic water filter with $20 \mathrm{wt} . \%$ addition of activated carbon. The adhesion force is equal to $170 \mathrm{nN}$. On the other hand, lead has a strong affinity for the ceramic water filter with $20 \mathrm{wt}$.\% addition of hydroxyapatite. The adhesion force between the ceramic water filter and lead is equal to $153 \mathrm{nN}$. Finally, the ceramic water filter

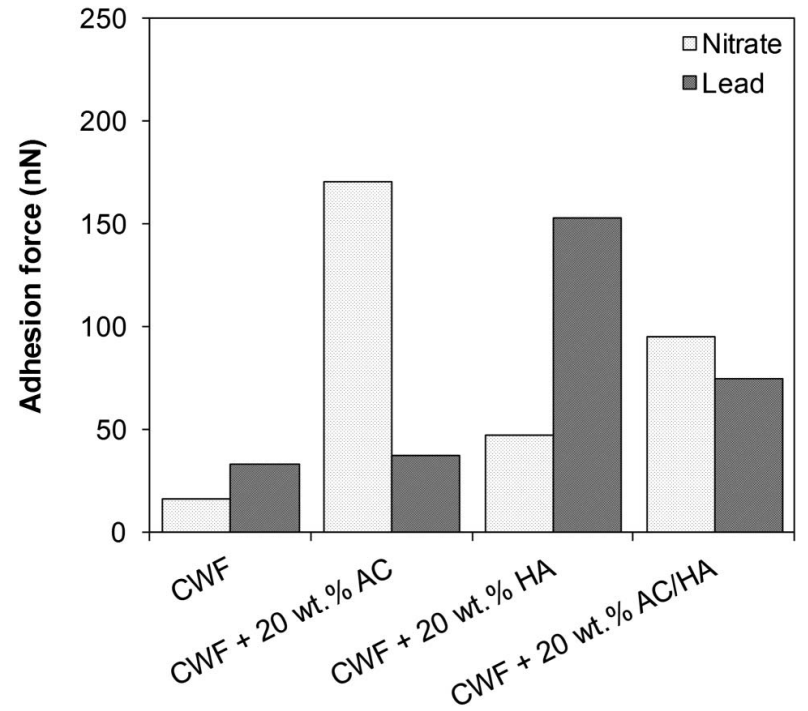

Fig. 6. Adhesion forces between the contaminants (nitrate and lead) and the CWF without additives and the CWF with $20 \mathrm{wt} . \%$ addition of $\mathrm{AC}, \mathrm{HA}$, or $\mathrm{AC} / \mathrm{HA}$. Data were obtained using atomic force microscopy (AFM).

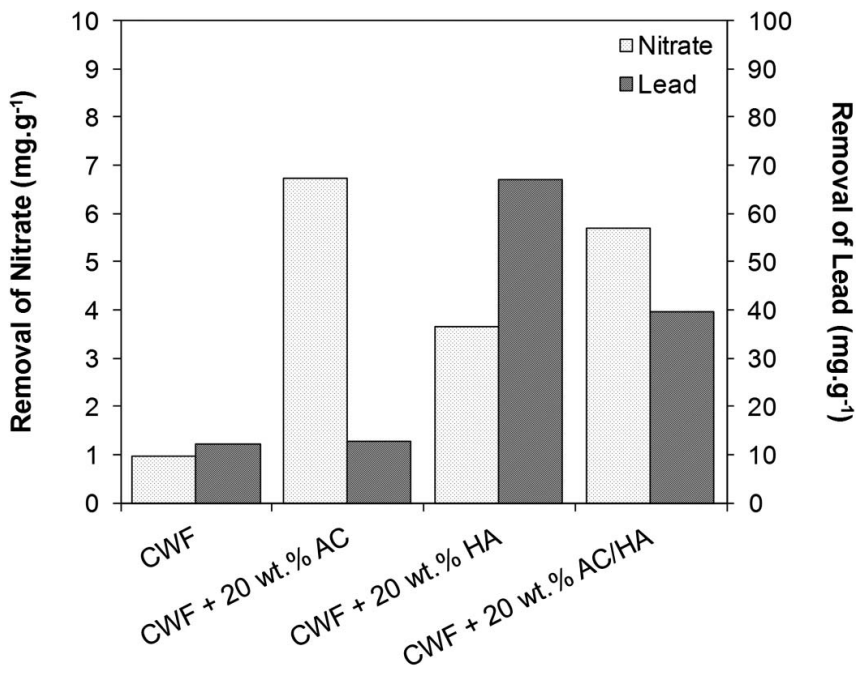

Fig. 7. Efficiency of the CWF without additives and the CWF with 20 wt. \% addition of AC, HA, or AC/HA in the removal of nitrate and lead. Data were obtained using ion chromatography (IC) and inductively coupled plasma mass spectrometry (ICP-MS).

with $20 \mathrm{wt} . \%$ addition of activated carbon and hydroxyapatite has adhesion forces of 95 and $74 \mathrm{nN}$ with nitrate and lead, respectively. These values are slightly lower than those with an exclusive addition of activated carbon or hydroxyapatite. However, it remains advantageous to remove organic and inorganic contaminants using this single composite material.

The removal efficiencies of the ceramic water filters obtained after firing at $950^{\circ} \mathrm{C}$ are presented in Fig. 7. The results show that the ceramic water filter without additives has limited efficiencies of 0.9 and $12.2 \mathrm{mg} \cdot \mathrm{g}^{-1}$ in the removal of nitrate and lead, respectively. This is due to the fact that nitrate and lead do not have strong affinities for this material (Fig. 6). In fact, nitrate and lead are only removed by physical trapping in the pores. The $20 \mathrm{wt} . \%$ addition of 


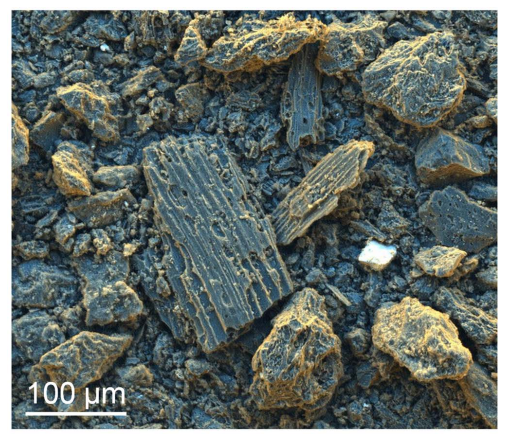

(a)

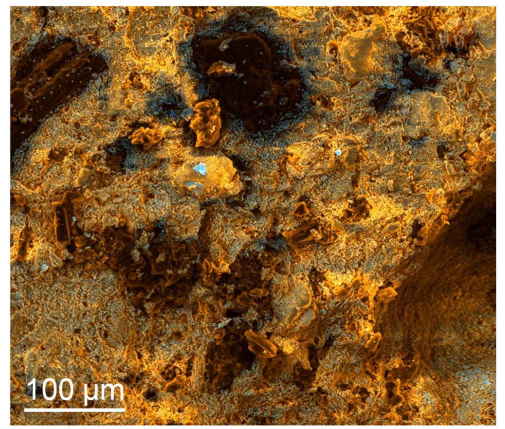

(b)

Fig. 8. DDC-SEM micrographs of (a) activated carbon; and (b) cross section of CWF with 20 wt.\% addition of activated carbon after the removal of nitrate.

activated carbon increases the affinity of nitrate for the material. It results in an important efficiency of $6.7 \mathrm{mg} \cdot \mathrm{g}^{-1}$ of the ceramic water filter with $20 \mathrm{wt} . \%$ addition of activated carbon in the removal of nitrate. On the other hand, the ceramic water filter with 20 wt.\% addition of hydroxyapatite has a high efficiency in the removal of lead. The efficiency is equal to $67.1 \mathrm{mg} \cdot \mathrm{g}^{-1}$ for a 20 wt.\% addition of hydroxyapatite, which is consistent with the results from the literature for hydroxyapatite (Baillez et al. 2007; Thuan et al. 2017). As a result, the ceramic water filter with $20 \mathrm{wt}$. $\%$ addition of activated carbon and hydroxyapatite has a high efficiency in the removal of both nitrate (i.e., $5.7 \mathrm{mg} \cdot \mathrm{g}^{-1}$ ) and lead (i.e., $39.5 \mathrm{mg} \cdot \mathrm{g}^{-1}$ ). The removal efficiency is controlled by the affinity of the contaminants for the additives in the ceramic water filters. Nevertheless, the removal efficiency of the ceramic water filters with additives remains higher for lead than nitrate (even accounting for the differences in the molecular weight of the additives).

The DDC-SEM micrographs of the activated carbon and the cross section of the ceramic water filter with $20 \mathrm{wt} . \%$ addition of activated carbon, both after nitrate removal, are presented in Fig. 8. It can be observed that the activated carbon is shaded [Fig. 8(a)], and the activated carbon in the ceramic water filter is only shaded at its edges [Fig. 8(b)]. This means that this shading is associated with nitrate. Typically, nitrate is removed from water via a surface-based mechanism of adsorption. The extent of the removal is limited by the specific surface area of the activated carbon. Once the surface of the activated carbon is covered, no more removal of nitrate can occur.

The X-ray diffraction patterns obtained prior to and after the removal of lead by the hydroxyapatite are presented in Fig. 9. The results show that several peaks associated with hydroxyapatite (e.g., at $3.9^{\circ}, 8.3^{\circ}$, and $13.4^{\circ}$ ) disappear in the X-ray diffraction

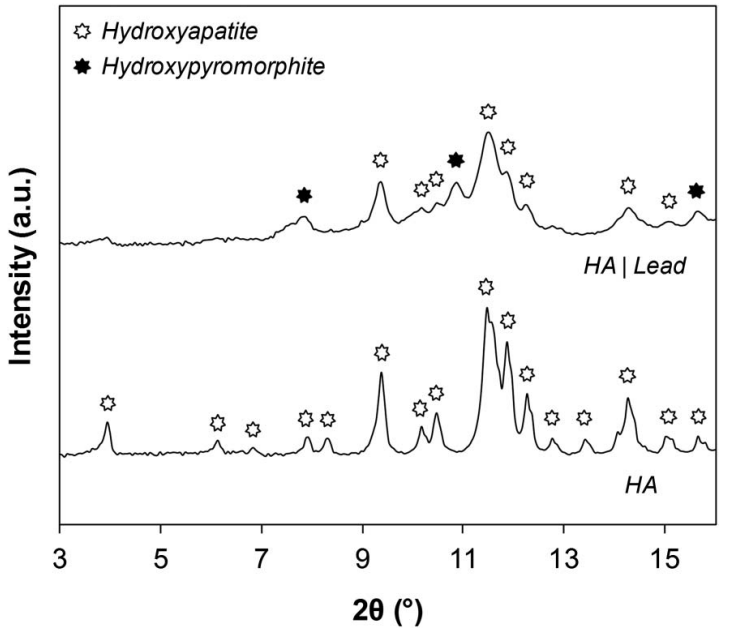

Fig. 9. Stacked plot of the X-ray diffraction patterns of the hydroxyapatite and the hydroxyapatite after the removal of lead (HA I lead) obtained using a silver radiation source.

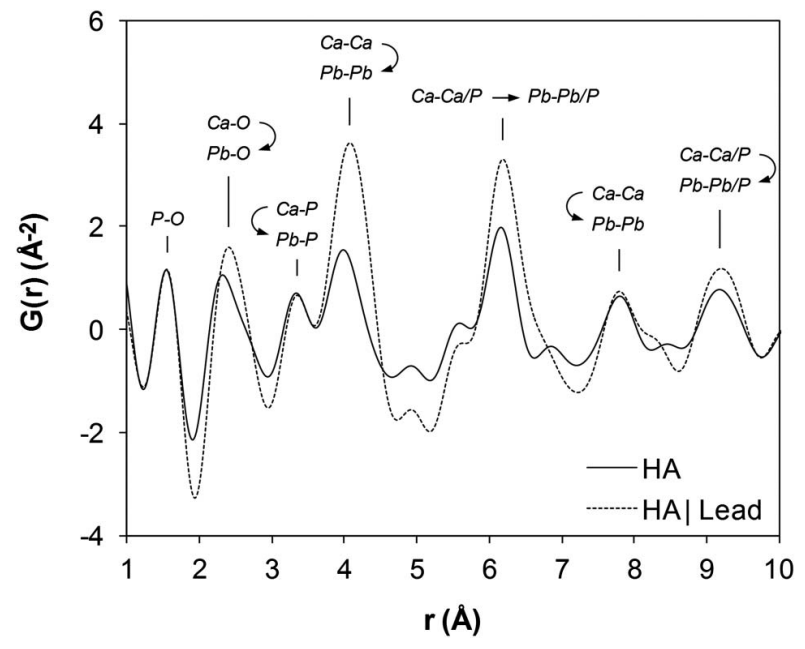

Fig. 10. X-ray pair distribution function curves of the hydroxyapatite and the HA I lead. Data were scaled to the nearest-neighbor P-O atom-atom correlation.

pattern after lead removal. Concurrently, new peaks associated with hydroxypyromorphite (e.g., at $7.8^{\circ}, 10.9^{\circ}$, and $15.6^{\circ}$ ) emerge. This means that the removal of lead induces a transformation of hydroxyapatite $\left[\mathrm{Ca}_{5}\left(\mathrm{PO}_{4}\right)_{3}(\mathrm{OH})\right]$ to hydroxypyromorphite $\left[\mathrm{Pb}_{5}\left(\mathrm{PO}_{4}\right)_{3}(\mathrm{OH})\right]$, where $\mathrm{Pb}$ atoms replace $\mathrm{Ca}$ atoms in the phosphate-based structure (Kamiishi and Utsunomiya 2013).

The X-ray pair distribution function curves obtained prior to and after the removal of lead by the hydroxyapatite are presented in Fig. 10. Prior to the removal of lead, the atom-atom correlations of the PDF curve are associated with the hydroxyapatite. The P-O bonds of hydroxyapatite are represented by the peak at $1.54 \AA$, whereas the peak at $2.32 \AA$ can be attributed to the $\mathrm{Ca}-\mathrm{O}$ bonds. The distances between the calcium atoms $(\mathrm{Ca}-\mathrm{Ca})$ and the calcium and phosphorous atoms $(\mathrm{Ca}-\mathrm{P})$ are also represented by the peaks at 4.0 and $3.3 \AA$, respectively. After lead removal, the atom-atom correlations of the PDF curve are directly associated with hydroxypyromorphite. The $r$ spacings of the 


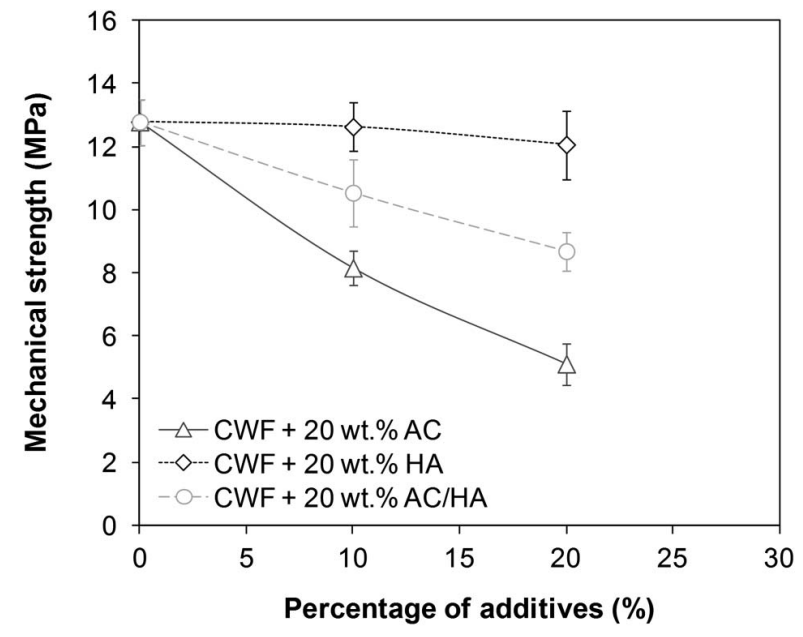

Fig. 11. Dependence of the mechanical strength of CWF on the percentage of AC, HA, and AC/HA. Data were obtained using a threepoint-bending test configuration.

atom-atom correlations are also equivalent to those of hydroxyapatite. This means that lead is removed from the aqueous solution by substitution with calcium from hydroxyapatite in the ceramic water filter (Smičiklas et al. 2008). In contrast with the adsorption, the elemental substitutions are not limited by the specific surface area of the ceramic water filters. This explains the higher efficiency of the ceramic water filter with $20 \mathrm{wt} . \%$ addition of activated carbon and hydroxyapatite in the removal of lead (i.e., $39.5 \mathrm{mg} \cdot \mathrm{g}^{-1}$ ) than in the removal of nitrate (i.e., $5.7 \mathrm{mg} \cdot \mathrm{g}^{-1}$ ), even though these contaminants have similar affinities for the respective additives.

\section{Mechanical Strength}

The dependence of the mechanical strengths of the ceramic water filters on the percentage of additives is presented in Fig. 11. The results indicate that the ceramic water filter without additives has a mechanical strength of $12.8 \mathrm{MPa}$ after firing at a temperature of $950^{\circ} \mathrm{C}$. In fact, this value represents a combination between the binding effect of the clay particles and the presence of large defects, such as the 50-200 $\mu \mathrm{m}$ decohesions around the quartz particles (Fig. 3). The addition of activated carbon or hydroxyapatite to the ceramic water filter results in a decrease of the mechanical strength. However, the decrease in the mechanical strength strongly depends on the particle size of the additives. The $20 \mathrm{wt} . \%$ addition of activated carbon with large particles of $60 \mu \mathrm{m}$ decreases the mechanical strength by $60 \%$. On the other hand, the mechanical strength only decreases by $5 \%$ for a $20 \mathrm{wt} \%$ addition of hydroxyapatite (small particles of $5 \mu \mathrm{m}$ ). The addition of activated carbon and hydroxyapatite results in a combination of the respective effects. The mechanical strength of the ceramic water filter decreases by $32 \%$ for a 20 wt. $\%$ addition of activated carbon and hydroxyapatite. Hence, the ceramic water filters have a mechanical strength of $8.7 \mathrm{MPa}$ after firing at the temperature of $950^{\circ} \mathrm{C}$. This value is slightly lower than the values from the literature (Plappally et al. 2011). Nevertheless, it is regarded as acceptable for such an application in household water treatment. This can be attributed to the distribution of the mechanical strength.

The distribution of the mechanical strength for the ceramic water filter is presented in Fig. 12. The results show that the ceramic water filter fails at stress levels between 7.0 and $10.0 \mathrm{MPa}$, with a maximum frequency of failure occurring at a stress level of

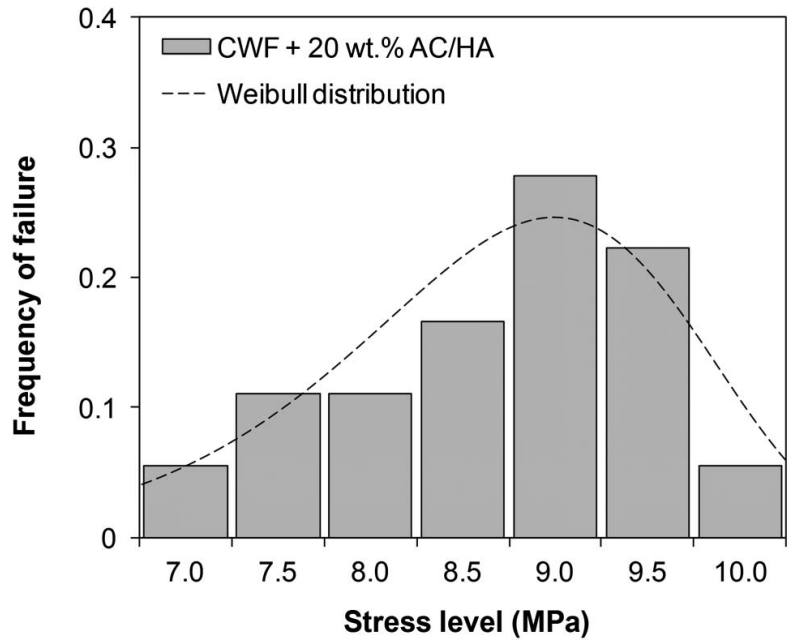

Fig. 12. Distribution of the mechanical strength of CWF with $20 \mathrm{wt} . \%$ addition of AC/HA. Data were obtained using a three-point-bending test configuration.

9.0 MPa. It can also be observed that the strength distribution is relatively well predicted by the Weibull distribution. In fact, the probability density function [Eq. (7)] confirms that failure does not occur at stress levels below 7.0 MPa.

\section{Implications}

The implications of this research are significant for the use of ceramic water filters in the purification of drinking water. Until now, ceramic water filters have only been used for the removal of microbial contaminants such as bacteria with water remaining unsafe to drink due to the presence of chemical substances. This work shows that chemical substances can be removed from drinking water by doping the ceramic water filters with organic (i.e., activated carbon) and inorganic (i.e., hydroxyapatite) additives. The doped ceramic water filters removed both organic (e.g., nitrate) and inorganic (e.g., lead) contaminants through a combination of trapping, adsorption, and substitution mechanisms. The efficiency of the ceramic water filters with a $20 \mathrm{wt} . \%$ addition of activated carbon and hydroxyapatite in the removal of nitrate and lead were equal to 5.7 and $39.5 \mathrm{mg} \cdot \mathrm{g}^{-1}$, respectively. Using frustum-shape filters of approximately $2 \mathrm{~kg}$, up to $8 \mathrm{~g}$ of lead could be removed from contaminated water. This means that 8,000 L of water (high lead levels of $1 \mathrm{mg} / \mathrm{L}$ ) may be purified by each filter (Ignatius et al. 2012). In fact, each filter could purify up to $20 \mathrm{~L}$ of water per day over a year, corresponding to the daily consumption of potable water for a family of six.

\section{Conclusions}

In this paper, the removal mechanisms of organic (e.g., nitrate) and inorganic (e.g., lead) contaminants were investigated in ceramic water filters with organic (i.e., activated carbon) and inorganic (i.e., hydroxyapatite) additives. Salient conclusions arising from this study are summarized below:

- The organic and inorganic additives are relatively well dispersed in the ceramic water filters. Their initial dimensions and properties are conserved at firing temperatures up to $950^{\circ} \mathrm{C}$. The ceramic water filters incorporating organic and inorganic additives are seen to have a greater volume fraction of connected pores, permeability, and specific surface area. 
- The organic (e.g., nitrate) and inorganic (e.g., lead) contaminants have strong adhesive interactions with ceramic water filters that contain organic and inorganic additives, respectively. This results in an increase of the efficiencies from 0.9 to $6.7 \mathrm{mg} \cdot \mathrm{g}^{-1}$ and 12.2 to $67.1 \mathrm{mg} \cdot \mathrm{g}^{-1}$ in the removal of nitrate and lead from water using $20 \mathrm{wt} . \%$ addition of activated carbon or hydroxyapatite.

- The removal of nitrate and lead was firstly achieved via trapping within the pores of the ceramic water filters. Nitrate was then seen to be adsorbed on the surface of the activated carbon. Lead was also substituting for calcium atoms in the hydroxyapatite structure to form hydroxypyromorphite.

- Ceramic water filters incorporating organic and inorganic additives removed a wide range of chemical substances from water. The removal involved a combination of trapping, adsorption, and substitution mechanisms. The ceramic water filters also had a relatively high mechanical strength of $8.7 \mathrm{MPa}$. In addition, the distribution of the mechanical strength was well predicted by the Weibull distribution.

\section{Acknowledgments}

The authors would like to acknowledge the CARNOT Mines Institute, SOLSTICE Laboratory of Excellence, and RAPSODEE Research Center at Mines Albi for financial support. The authors are also grateful to the management and staff of the Department of Mechanical and Aerospace Engineering, Department of Civil and Environmental Engineering, and the Andlinger Center for Energy and the Environment at Princeton University, as well as the Department of Mechanical Engineering at WPI for their assistance with the research. Mr. Kai Gong is also thanked for performing the $\mathrm{X}$-ray diffraction measurements in this study.

\section{References}

Annan, E., K. Mustapha, O. S. Odusanya, K. Malatesta, and W. O. Soboyejo. 2014. "Statistics of flow and the scaling of ceramic water filters.” J. Environ. Eng. 140 (11): 04014039. https://doi.org/10.1061 /(ASCE)EE.1943-7870.0000862.

Ashbolt, N. J. 2004. "Microbial contamination of drinking water and disease outcomes in developing regions." Toxicology 198 (1-3): 229-238. https://doi.org/10.1016/j.tox.2004.01.030.

ASTM. 2010. Standard test methods for flexural properties of unreinforced and reinforced plastics and electrical insulating materials. ASTM D790. West Conshohocken, PA: ASTM.

Baillez, S., A. Nzihou, D. Bernache-Assolant, E. Champion, and P. Sharrock. 2007. "Removal of aqueous lead ions by hydroxyapatites: Equilibria and kinetic processes." J. Hazard. Mater. 139 (3): 443-446. https://doi.org/10.1016/j.jhazmat.2006.02.039.

Barrett, E. P., L. G. Joyner, and P. Halenda. 1951. "The determination of pore volume and area distributions in porous substances. I: Computations from nitrogen isotherms." J. Am. Chem. Soc. 73 (1): 373-380. https://doi.org/10.1021/ja01145a126.

Brown, J. M., S. Proum, and M. D. Sobsey. 2008. "Escherichia coli in household drinking water and diarrheal disease risk: Evidence from Cambodia." Water Sci. Technol. 58 (4): 757-763. https://doi.org/10 .2166/wst.2008.439.

Brunauer, S., P. H. Emmett, and E. Teller. 1938. "Adsorption of gases in multimolecular layers.” J. Am. Chem. Soc. 60 (2): 309-319. https://doi .org/10.1021/ja01269a023.

Choudhary, G., R. K. Sharma, and A. K. Plappally. 2014. "Local material composite sintered systems for fluoride removal." Desalin. Water. Treat. 55 (10): 2626-2637. https://doi.org/10.1080/19443994.2014 .957936 .

Clasen, T., W. P. Schmidt, T. Rabie, I. Roberts, and S. Cairncross. 2007. "Interventions to improve water quality for preventing diarrhea:
Systematic review and meta-analysis." Brit. Med. J. 334 (7597): 782-785. https://doi.org/10.1136/bmj.39118.489931.BE.

Davies, I. J. 2017. "Unbiased estimation of the Weibull scale parameter using linear squares analysis.” J. Eur. Ceram. Soc. 37 (8): 2973-2981. https://doi.org/10.1016/j.jeurceramsoc.2017.03.015.

Di Blasi, C. 2008. "Modeling chemical and physical processes of wood and biomass pyrolysis." Prog. Energy Combust. Sci. 34 (1): 47-90. https://doi.org/10.1016/j.pecs.2006.12.001.

Fewtrell, L., R. B. Kaufmann, D. Kay, W. Enanoria, L. Haller, and J. M. Colford Jr. 2005. "Water, sanitation, and hygiene intervention to reduce diarrhea in less developed countries: A systematic review and metaanalysis." Lancet Infect. Dis. 5 (1): 42-52. https://doi.org/10.1016 /S1473-3099(04)01253-8.

Franco, E., C. Meleleo, L. Serino, D. Sorbara, and L. Zaratti. 2012. "Hepatitis A: Epidemiology and prevention in developing countries." World J. Hepatol. 4 (3): 68-73. https://doi.org/10.4254/wjh.v4 .i3.68.

Hunter, P. R. 2009. "Household water treatment in developing countries: Comparing different interventions types using meta-regression." Environ. Sci. Technol. 43 (23): 8991-8997. https://doi.org/10.1021 les9028217.

Ignatius, C. M., E. N. Emeka, J. I. Ebele, I. O. Otuu, A. U. Silas, and A. O. Edwin. 2012. "Lead in potable water sources in Abakaliki Metropolis, South-East, Nigeria.” Bull. Environ. Contam. Toxicol. 88 (5): 793-796. https://doi.org/10.1007/s00128-012-0532-z.

Järup, L. 2003. "Hazards of heavy metal contamination." Br. Med. Bull. 68 (1): 167-182. https://doi.org/10.1093/bmb/ldg032.

Kamiishi, E., and S. Utsunomiya. 2013. "Nano-scale reaction processes at the interface between apatite and aqueous lead." Chem. Geol. 340: 121-130. https://doi.org/10.1016/j.chemgeo.2012.12.019.

Katz, A. J., and A. H. Thompson. 1987. "Prediction of rock electrical conductivity from mercury injection measurements." J. Geophys. Res. 92 (B1): 599-607. https://doi.org/10.1029/JB092iB01p00599.

McGuigan, K. G., T. M. Joyce, and R. M. Conroy. 1999. "Solar disinfection: Use of sunlight to decontaminate drinking water in developing countries." J. Med. Microbiol. 48 (9): 785-787. https://doi.org/10 .1099/00222615-48-9-785.

Meenakshi, A., and R. C. Maheshwari. 2006. "Fluoride in drinking water and its removal." J. Hazard. Mater. 137 (1): 456-463. https://doi.org/10 .1016/j.jhazmat.2006.02.024.

Nishiyama, N., and T. Yokoyama. 2014. "Estimation of permeability of sedimentary rocks by applying water-expulsion porosimetry to Katz and Thompson model." Eng. Geol. 177: 75-82. https://doi.org/10 .1016/j.enggeo.2014.05.016.

Oyanedel-Craver, V. A., and J. A. Smith. 2008. "Sustainable colloidalsilver-impregnated ceramic filter for point-of-use water treatment." Environ. Sci. Technol. 42 (3): 927-933. https://doi.org/10.1021 les071268u.

Plappally, A., I. Yakub, L. C. Brown, W. Soboyejo, and A. B. O. Soboyejo. 2011. "Physical properties of porous clay ceramic-ware." J. Eng. Mater. Technol. 133 (3): 031004. https://doi.org/10.1115/1.4004158.

Prater, C. B., P. G. Maivald, K. J. Kjoller, and M. G. Heaton. 1995. "Probing nano-scale forces with the atomic force microscope." In Digital instruments: Application note. Chadds Ford, PA: Veeco Metrology Group.

Qiu, X., J. W. Thompson, and S. J. L. Billinge. 2004. "PDFgetX2: A GUI-driven program to obtain the pair distribution function from X-ray powder diffraction data." J. Appl. Cryst. 37 (4): 678. https://doi .org/10.1107/S0021889804011744.

Smičiklas, I., A. Onjia, S. Raičević, D. Janaćković, and M. Mitrić. 2008. "Factors influencing the removal of divalent cations by hydroxyapatite." J. Hazard. Mater. 152 (2): 876-884. https://doi.org/10.1016/j.jhazmat 2007.07.056.

Sobsey, M. D., C. E. Stauber, L. M. Casanova, J. M. Brown, and M. A. Elliott. 2008. "Point of use household drinking water filtration: A practical, effective solution for providing sustained access to safe drinking water in the developing world." Environ. Sci. Technol. 42 (12): 42614267. https://doi.org/10.1021/es702746n.

Sullivan, R. K., M. Erickson, and V. A. Oyanedel-Craver. 2017. "Understanding the microbiological, organic and inorganic contaminant 
removal capacity of ceramic water filters doped with different silver nanoparticles.” Environ. Sci. Nanomater. 4 (12): 2348-2355. https://doi .org/10.1039/C7EN00443E.

Tarvornpanich, T., G. P. Souza, and W. E. Lee. 2008. "Microstructural evolution in clay-based ceramics. II: Ternary and quaternary mixtures of clay, flux, and quartz filler." J. Am. Ceram. Soc. 91 (7): 2272-2280. https://doi.org/10.1111/j.1551-2916.2008.02394.x.

Thuan, L. V., D. V. Dat, P. C. Nguyen, and M. A. Trubitsyn. 2017. "Synthesis of calcium-deficient carbonated hydroxyapatite as promising sorbent for removal of lead ions." J. Nano. R. 45: 124-133. https:// doi.org/10.4028/www.scientific.net/JNanoR.45.124.

Weibull, W. 1951. "A statistical distribution function of wide applicability." J. Appl. Mech. 18: 293-297.
WHO (World Health Organization). 2001. Water for health-Taking charge. World Water Day Rep. Geneva: WHO.

WHO (World Health Organization). 2015. Progress on sanitation and drinking water. 2015 update and MDG assessment. Geneva: WHO.

Yakub, I., et al. 2013. "Porosity, flow, and filtration characteristics of frustum-shaped ceramic water filters." J. Environ. Eng. 139 (7): 986-994. https://doi.org/10.1061/(ASCE)EE.1943-7870.0000669.

Yakub, I., and W. Soboyejo. 2012. "Adhesion of E. coli to silver or copper coated porous clay ceramic surfaces.” J. Appl. Phys. 111 (12): 124324. https://doi.org/10.1063/1.4722326.

Yakub, I., and W. Soboyejo. 2013. "Adsorption of fluoride from water using sintered clay-hydroxyapatite composites." J. Environ. Eng. 139 (7): 995-1003. https://doi.org/10.1061/(ASCE)EE.1943-7870.0000692. 